\title{
ЛИТЕРАТУРОВЕДЕНИЕ
}

\author{
УДК 812.112 .5
}

\section{И.М. Михайлова}

Санкт-Петербургский государственный университет

\section{ГОД 1917. ОКТЯБРЬСКАЯ РЕВОЛЮЦИЯ В СТИХАХ ГОЛЛАНДСКИХ СОРАТНИКОВ ЛЕНИНА}

Из многочисленных фактов, свидетельствующих об интересе нидерландских писателей к общественно-политическим идеям российской интеллигенции на рубеже XIX-XX вв., в центре внимания статьи находится поэтическое творчество двух поэтов-коммунистов: Хермана Гортера (1864-1927) и Хенриетты Роланд Холст ван дер Схалк (1869-1952). Оба поэта занимают важное место в истории нидерландской литературы, оба пришли к марксизму в результате преодоления личного кризиса, в поисках выхода из тупика индивидуализма. Оба поэта были соратниками Ленина по международному социал-демократическому движению до 1917 г., затем по Коминтерну. Ленин и общался с ними лично, и переписывался: ленинские письма 1915-1916 гг., адресованные Гортеру и Роланд Холст, свидетельствуют об их идейной близости и деловом сотрудничестве. Оба голландских поэта-коммуниста продолжали писать искренние лирические стихи также в период увлечения политической деятельностью. Знакомство с этой лирикой позволяет заглянуть в их внутренний мир и попытаться понять, как именно эти двое представителей европейских социалистов и коммунистов видели революцию, к каким идеалам они стремились. Выясняется, что их идеалы были полностью абстрактными: поэты восхищаются гармонией между освобожденным рабочим классом и музыкой природы, у обоих поэтов пролетариат, победивший в революции, нередко изображается водящим хоровод. Судьбы конкретных людей ни в коей мере не были для них точкой отсчета. Они так и не сделались борцами за реальные интересы трудящихся, а остались в первую очередь эстетами.

Ключевые слова: нидерландская поэзия, Гортер, Хенриетта Роланд Холст, Октябрьская революция, Коммунистический интернационал, Ленин. 


\section{Irina Michajlova}

St. Petersburg State University

\section{OCTOBER REVOLUTION AND LENIN IN THE VERSES OF HIS DUTCH COMRADES}

There are numerous facts that demonstrate the interest of Dutch writers in the social and political ideas of the Russian intelligentsia at the turn of the nineteenth and twentieth centuries. The focus of this article is the poetic work of the two communist poets: Herman Gorter (1864-1927) and Henriette Roland Holst (1869-1952). Both poets occupy an important place in the history of Dutch literature, both came to Marxism as a result of overcoming the personal crisis, in search of a way out of the impasse of individualism. Both poets were Lenin's comrades in the international social-democratic movement before 1917, then in the Communist International. Lenin corresponded with both poets and communicated with them personally: Lenin's letters of 1915 and 1916, addressed to Gorter and Roland Holst, show their ideological unity and close cooperation. Both Dutch communist poets continued to write lyrical verses also during the period of political activity. Reading these lyrics allows us to look into their inner world and to understand exactly how these two representatives of the European socialists and communists saw the revolution, to what ideals they aspired. It turns out that their ideals were completely abstract: the poets admire the harmony between the liberated working class and the music of nature, both often depict the proletariat, who won the revolution, as dancing a round dance. The lives of real people were in no way their starting point.

Keywords: Dutch poetry, Gorter, Henriette Roland Holst, October Revolution, Communist International, Lenin.

\section{ВВЕДЕНИЕ}

На рубеже XIX-XX вв. в творчестве целого ряда нидерландских писателей отразился их интерес к России, в первую очередь к общественно-политическим идеям российской интеллигенции. Вспомним, что Гаагская мирная конференция 1899 г. была созвана по инициативе российского императора Николая II в надежде добиться объединенными усилиями разрядки той грозовой атмосферы, которая царила в Европе на рубеже веков. С именем русского царя связано также решение создать Постоянную палату третейского суда, для которой в 1913 г. и был построен Дворец мира в Гааге, известный в наше время как резиденция Международного суда ООН.

Нидерландских авторов рассматриваемого периода задевали за живое такие разные проявления российской общественно-политической мысли, как идея всеобщего мира, носителем которой виделся Николай II (Л.Куперус «Их величества» и «Всеобщий мир», см.: [Gemeren, 2016, p.223]), идеи анархизма в духе Бакунина и Кро- 
поткина (Л.Куперус «Метаморфоза»), разумеется, толстовство (Стейн Стрёвелс), а также социал-демократические идеи борьбы против социального неравенства (Х. Хейеманс «Агасфер») и, наконец, ленинские идеи социалистической революции и победы коммунизма. Мы остановимся на последнем моменте - отражении революционной проблематики в поэзии двух поэтов-коммунистов - Хермана Гортера и Хенриетты Роланд Холст, или Генриетты Роланд-Гольст, как это имя передается в Полном собрании сочинений Ленина. Хотя эта тема ранее уже затрагивалась в отечественном литературоведении [Ошис, 1994], ее нельзя считать исчерпанной. Задача настоящей статьи - по письмам Ленина проследить его отношение к Гортеру и Роланд Холст как соратникам и затем выявить на основе их поэтического творчества, каким они, поэты-лирики, видели то светлое будущее, за которое боролись как политики.

\section{РОЛЬ ХЕРМАНА ГОРТЕРА И ХЕНРИЕТТЫ РОЛАНД ХОЛСТ В НИДЕРЛАНДСКОЙ ЛИТЕРАТУРЕ}

И Херман Гортер, и Хенриетта Роланд Холст - важнейшие имена в истории нидерландской словесности [От «Лиса Рейнарда» до «Сна богов», 2013, с. 360-362, 388-401]. Гортер заслуженно считается крупнейшим поэтом из поколения «восьмидесятников» литераторов, начавших литературную деятельность в 1880-е годы и провозгласивших принципы искусства ради искусства, служения красоте, первостепенности индивидуального начала в творчестве. По значимости и по месту в литературном процессе Нидерландов этот блистательный период можно сравнить с Серебряным веком в русской литературе.

Генриетта Роланд Холст, дебютировавшая позднее, поразила современников монументальным звучанием и философской глубиной уже своего первого сборника «Сонеты и стихи, написанные терцинами» (1896), в котором прочитывалось ее увлечение Данте и Платоном. На протяжении всей своей долгой творческой биографии она оставалась общепризнанным мастером слова, о чем свидетельствует тот факт, что в 1952 г. нидерландский ПЕН-центр номинировал ее на Нобелевскую премию по литературе ${ }^{1}$.

${ }^{1}$ Об этом можно прочитать на сайте Нобелевской премии: http://www. nobelprize.org/nomination/archive/show_people.php?id=12039. 
Оба поэта пришли к социализму после мучительных поисков выхода из духовного кризиса, в котором оказались в результате доведенного до логического завершения принципа творческого индивидуализма. Сначала этика Спинозы, затем учение Маркса стали базисом их нового идеала - стремления добиться освобождения рабочего класса и, как они считали, восстановления первоначальной гармонии между человечеством и силами природы.

\section{ХЕРМАН ГОРТЕР И ХЕНРИЕТТА РОЛАНД ХОЛСТ КАК ПОЛИТИКИ}

Увлекшись политикой, оба поэта вскоре стали заметными фигурами в международном социал-демократическом, а позднее коммунистическом движении. Перечислим предельно кратко важнейшие факты их политической биографии.

Гортер, вступив в Социал-демократическую партию Нидерландов, с 1897 по 1907 г. руководил революционным марксистским журналом «De Nieuwe Tijd» («Новое время»). В 1904 г. перевел на нидерландский язык «Манифест коммунистической партии». В 1908 г. написал брошюру для рабочих «Исторический материализм» (1908), которую высоко оценил В.И.Ленин; в 1919 г. она была издана в Москве по-русски [Гортер, 1919] и уже в наше время, в 2011 г., переиздана издательством «Либроком» [Гортер, 2011]. В годы Первой мировой войны занимал интернационалистскую позицию, о чем в 1914 г. и написал свою вторую знаменитую книгу «Империализм, мировая война и социал-демократия» (рус. пер.: [Гортер, 1920]). В 1917 г. приветствовал Октябрьскую революцию, в 1918 г. принял участие в создании Коммунистической партии Нидерландов, а в 1919-1921 - Коммунистической рабочей партии Германии. В 1920 г. написал имевшее большой резонанс «Открытое письмо товарищу Ленину» (1920), явившееся ответом на ленинскую работу «Детская болезнь левизны в коммунизме». В 1921 г. участвовал в III Конгрессе Коминтерна в Москве в составе делегации Коммунистической партии Германии, в 1922-м отошел от активной политической деятельности, но в поэзии продолжал воспевать коммунистические идеалы.

Х. Роланд Холст с 1889 г. совместно с Гортером редактировала журнал «De Nieuwe Tijd», в 1900-м была делегирована от Нидерландов во Второй интернационал, где тесно общалась с Р. Люксем- 
бург, К. Либкнехтом, Л. Троцким. В этом же году перевела на нидерландский язык текст песни «Интернационал». В 1902 г. написала исследование «Капитал и труд в Нидерландах» - марксистскую историю становления и развития капитализма в стране. Во время Первой мировой войны вела антивоенную пропаганду и участвовала в Циммервальдской конференции. Как и Гортер, приняла Октябрьскую революцию с восторгом, вместе с ним стояла у истоков Коммунистической партии Голландии и тоже посетила Москву в 1921 г. для участия в конгрессе Коминтерна. Узнав о голоде в Советской России, по возвращении в Голландию организовала сбор денег для помощи голодающим. Оставалась членом КПГ до 1927 г., но вышла из нее, когда узнала о судьбе Троцкого.

\section{ПИСЬМА ЛЕНИНА}

Начало активной переписки Ленина с Гортером и Роланд Холст относится к 1914-1916 гг., когда вождь мирового пролетариата жил в Швейцарии и уделял большое внимание борьбе с оппортунизмом в духе Каутского в защиту левых элементов. Если Гортера он однозначно считает «честным марксистом», то Роланд Холст вызывает у него больше сомнений. Он то ссылается на нее как на свою сторонницу, как в письме о нидерландском социал-демократе Трулстре (письмо А. Г. Шляпникову от 27.10.1914), то называет ее оппортунисткой и «каутскианкой», как в письме к А. М. Коллонтай от 4.08.1915:

О, этот Трульстра оппортунист половчее «добренького» старичка Каутского! Как маневрировал этот Трульстра, чтобы выгнать из голландской партии честных людей и марксистов (Гортера, Паннекука, Вайнкопа)!! Никогда не забуду, как Роланд-Гольст, бывшая у меня однажды в Париже, сказала про Трульстру: «еin hundsgemeiner Kerl» [Ленин, 1970, с. 21].

Роланд-Гольст, как и Раковский (видали его франиузскую брошюру?), как и Троикий, по-моему, все вреднейшие «каутскианцы» в том смысле, что все в разных формах за единство с оппортунистами, все в разных формах приукрашивают оппортунизм, все проводят (по-разному) эклектииизм вместо революиионного марксизма [Ленин, 1970, с. 117-118]. 
Возможно, поэтому в письмах Ленина, адресованных Гортеру, ощущается значительно бо́льшая непринужденность, чем в письмах к Роланд Холст, неизменно настороженных. К Гортеру он обращается «товарищ Гортер» и заканчивает письма словами «сердечный привет», к Роланд Холст - просто «товарищ», и ни о каких «сердечных приветах» нет и речи. Письма Гортеру более разнообразны по тематике. В качестве примера приведем фрагмент письма к Гортеру от 05.05.1915 (речь в нем идет о брошюре «Империализм, мировая война и социал-демократия») и фрагмент письма к Роланд Холст от 8.03.1916, которое Ленин послал ей после разрешения разногласий о составе редакции журнала "Vorbote".

Уважаемый товарии, Гортер!

Товариш, Радек показал мне Ваше письмо. <...>

Радек говорит, что Ваша брошюра вышла на английском языке. Это меня очень радует: теперь я смогу все прочесть и понять. Голландский язык я понимаю приблизительно на 30-40\%. Поздравляю Вас с Вашими прекрасными атаками на оппортунизм и Каутского. Главная ошибка Троикого состоит в том, что он не нападает на эту банду.

Сердечный привет.

Ваш Н. Ленин

Mой aдpec: Wl. Uljanow. Waldheimstrasse 66. Bern.

Напишите мне открьтку, когда Вы приедете [Ленин, 1970, c. 74-75].

Дорогой товарищ! Прошу извинить меня, что я так поздно отвечаю на Ваше письмо. Я выступал с докладами в различных городах Швейиарии. Я очень благодарен Вам за Ваш любезный ответ. Буду очень рад, если наше сотрудничество пройдет без трений. <..>

В чем состоят наши разногласия с Троцким? Это Вас, наверное, интересует. В немногих словах: он каутскианеи, т.е. хочет единения с каутскианиами в Интернационале, с фракизей Чхеидзе в России. Мь решительно против такого единения. <...>

С лучшими приветами Вам, товарищу Паннекуку и другим голландским товарищзам.

Ваш Н. Ленин [Ленин, 1970, с. 189-192]. 


\section{СТИХИ О ЛЕНИНЕ}

Как Гортер, так и Роланд Холст писали стихи о Ленине, в которых каждый по-своему высказывал свое восхищение этим человеком. Стихи Гортера не издавались по-русски, поэтому приведем по-нидерландски, с русским подстрочником фрагмент стихотворения, в котором он описывает отдых вождя после одержанной победы.

Hij denkt aan den strijd. Hij wist er

De zege van. - Die was gister. -

Diep ademend herstelt hij zich.

Zwak voelt hij zich, ernstig.

Zoo was hij. Hij heeft het vaandel geplant,

Hoog op de bergen, naar het nieuwe land [Gorter, 1930, p. 60].

Он думает о борьбе. Он познал / победу в ней. - Она была вчера. / Глубоко дыииа, он отдыхает. / Чувствует себя слабым, серьезным. / Таким он был. Он водрузил знамя / высоко в горах, в новой стране.

Вероятно, стихотворение не переводилось на русский из-за недостаточно героического образа вождя. Да и образ победившего социализма как новой страны высоко в горах представляется сомнительным.

Стихотворение Х. Роланд Холст «Ленин» в переводе А.Янова, напротив, было напечатано дважды. Приведем его начало:

Где мне найти слова, чтоб описать вас, Ленин?

Ведь нужных слов еще никто не создал.

Создать их в состояньи лишь эпоха,

Которая рождается сегодня.

Они появятся, когда все люди

Единым крепким коллективом станут

[Роланд Холст, 1964, с. 93; 1980, с. 266]. 


\section{СТИХИ ГОРТЕРА О СОЦИАЛИЗМЕ}

Первый сборник социалистических стихов Гортера вышел в 1903 г., после этого он продолжал писать их до самой смерти, почти не заботясь об их издании (многие были опубликованы посмертно в 1930 г.). Приведем несколько примеров на нидерландском языке, с подстрочным переводом:

O lichtende gloed

Van het socialisme,

Verterend het kapitalisme

In zich, als de hemel de wolken doet [Gorter, 1930, p. 61].

О, светлое сияние / социализма, / растворяющее капитализм / в себе, как это делает небо с облаками.

Diep in den nacht

Hoor ik een dans,

Het is der arbeiders dans.

Ver in den nacht

Hoor ik muziek,

Het is der schoonheid muziek [Gorter, 1930, p. 39].

Глубоко в ночи / я сльшиу танеи, / это танеи, рабочих. / Далеко в ночи / я слышиу музыку, / это музыка красоты.

Читая эти стихи, нельзя не согласиться с В.В. Ошисом, написавшим: «Искренность и лиризм поэзии Гортера нередко входит в противоречие с отвлеченностью ее образов, перенасыщенностью символикой, и тут дело не только в неоромантической традиции “восьмидесятников", вскормившей Гортера-поэта, но и в его общей склонности к поэтическим абстракциям» (Ошис, 1994, с. 318).

\section{ЛИРИЧЕСКАЯ ДРАМА Х.РОЛАНД ХОЛСТ «ЖЕРТВА»}

Понимание проблематики Октябрьской революции Хенриеттой Роланд Холст наиболее полно отразилось ее «лирической драме» (как она сама назвала этот жанр), написанной в 1918-1921 гг,, с многозначительным названием «Жертва». В 1922 г. эта драма уже была переведена на русский и издана в Петрограде вместе с двумя другими пьесами Х. Роланд Холст [Роланд Гольст, 1922]. 
Место и время действия - Советская Россия, зима после революции. Главные действующие лица носят говорящие русские имена или фамилии: это народный комиссар Устойчив, Вера - мать Виктора, солдата, вернувшегося с фронта Первой мировой войны, сам Виктор и его невеста Люба. Как в античной трагедии, в «Жертве» выступают два хора: хор рабочих и хор работниц.

В первом действии Устойчив произносит пламенные речи о свободе, которую завоевал русский пролетариат, и о том, что эта свобода еще не есть настоящее счастье: пока русские рабочие одиноки в своей победе, пока их не поддержали рабочие других стран, ее могут уничтожить враги-капиталисты. Слушающие понимают, что их задача - раздуть искру свободолюбия в душах зарубежных товарищей. Виктор с Любой отправляются «дарить добытую свободу» братьям за границей.

В начале второго действия они возвращаются в Россию удрученные: европейские братья не откликнулись на их призыв. Более того, в конце второго действия приходит известие, что на Советскую Россию наступают соседние государства: «господа» заставили вчерашних рабочих, переодетых в солдатские шинели, взяться за оружие. Виктор воспринимает это как личную трагедию: что делать? В целях самозащиты тоже поднять оружие на тех, кого он считает своими братьями? Или не делать этого и дать себя убить? Вера разрешает его сомнения, советуя всем женщинам из хора уговорить своих сыновей, мужей или женихов пойти навстречу врагу без оружия, с открытыми лицами и протянутой для рукопожатия рукой. Женщины покидают сцену и вскоре возвращаются: «Каждая держит за руку сына, мужа или жениха: так они и проходят хороводом по сцене» [Roland Holst, 1921, p.79]. Мужчины отправляются брататься с врагом.

В начале третьего действия мы узнаем о той великой жертве, которую приходится принести матери и невесте ради победы социализма. Вестник сообщает, что иностранные солдаты, напавшие на Советскую Россию, даже не подумали вступить в диалог с Виктором и его сподвижниками и убили всех безоружных товарищей. Тут на сцену выходит комиссар Устойчив и объясняет, что если на тебя идут с оружием, то надо защищаться, но при этом не ожесточаться сердцем и помнить, что тот, с кем ты сегодня воюешь, твой брат, пока еще не успевший прозреть. Он обращается к Вере 
как матери, потерявшей все, что у нее было, с просьбой подтвердить его правоту. Вера соглашается с ним, и драма заканчивается сравнением революции с силами природы, по законам которой за приливом следует отлив, а потом новый прилив: несмотря на все сегодняшние тяготы, еще придет время, когда зарубежные братья захотят и смогут стать свободными.

После 1921 г. «Жертва» ни разу не переиздавалась и в наши дни полностью забыта. Текст пьесы, описывающей голод, вызванный революцией, и гибель мужа и всех детей Веры, сгоревших в огне борьбы, а также всех мужей и женихов хора работниц, не дает ответа на вопрос, почему эта не слишком оптимистическая трагедия была воспринята как прославление Великого Октября.

Из особенностей русского перевода драмы «Жертва», которые уже рассматривались ранее [Михайлова, 2008, с.142-146], отметим одну существенную неточность: важная для Х. Роланд Холст мысль о том, что русские рабочие, сбросившие иго и тем самым вырвавшиеся далеко вперед, не смогут продержаться долго без поддержки рабочих соседних стран, полностью затушевана.

\section{Oestoichyw}

Wij moeten dit volbrengen, make' in hen

vrijheidswil van een vonk een vlam, of wij

gaan onder, eenzaam gaan wij onder.

$<\ldots>$

\section{Een stem uit het koor}

Den wil der makkers te wekke' en te richten is voor mijn zwakte d'eenge medicijn [Roland Holst, 1921, p. 14].

\section{Дословный перевод:}

Устойчив: Мы должны это совершить, раздуть в них / искру воли к свободе в пламя, или мы / погибнем, в одиночестве погибнем. <..>

Голос из хора: Волю товарищей пробудить и направить - / это единственное лекарство от моей слабости.

\section{Опубликованньй перевод:}

\section{Устойчив}

Наш долг велит нам это совершить, Разжечь в пожар стремление к свободе,

Хотя б ценою гибели своей!

$<\ldots>$ 


\section{Голос из хора}

Но я мои исправлю заблужденья,

Я пробужу, зажгу сердца людей! [Роланд Гольст, 1922, с. 35-36].

\section{ЗАКЛЮЧЕНИЕ}

Таким образом, и Херман Гортер, и Хенриетта Роланд Холст в своих лирических произведениях изобразили совершенно абстрактную картину победы пролетариата, за которой не видно реальных человеческих проблем. Роланд Холст показала трагичность революционных событий, которую переосмыслила как оправданную жертву во имя великой сверхчеловеческой задачи. Оба поэта воспринимали пролетарскую революцию как природную силу и после 1917 г. еще долго не могли поверить, что революция ограничится масштабами одной страны и не станет всеобей.

\section{ЛИТЕРАТУРА}

Гортер Г. Исторический материализм. М.; Пг.: Коммунист, 1919. 140 с.; 2-е изд.: М.: Красная новь, 1924; 3-е изд.: М.: Либроком, 2011. 176 с.

Гортер Г. Империализм, мировая война и социал-демократия. М.: Госиздат, 1920. 152 c.

Ленин В. И. ПСС. 5-е изд. Т. 49. М.: Изд-во политической литературы, 1970. $724 \mathrm{c}$.

Михайлова И.М. О стратегии переводов нидерландской поэзии в раннее советское время // Известия Российского государственного педагогического университета им. А. И. Герцена. 2008. № 59. С. 142-146.

От «Лиса Рейнарда» до «Сна богов»: история нидерландской литературы. СПб.: Александрия, 2013. Т. 1. ХІІ - начало XX века. 544 с.

Ошис B. В. Под знаком социалистических идей: [Нидерландская литература на рубеже XIX и XX веков] // История всемирной литературы: В 8 т. М.: Наука, 1994. Т. 8. С. 316-318.

Роланд Гольст ван дер Схальк Г. Жертва / пер. В. Рейтц // Роланд Гольст ван дер Схальк Г. Лирические драмы. Пг.: Государственное издательство, 1922. C. 29-128.

Роланд Холст ван дер Схалк Г. Ленин / пер. А. Орлова // Ладонь поэта. Стихи. М.: Прогресс, 1964. С. 93-94.

Роланд Холст ван дер Схалк Г. Ленин / пер. А. Орлова // В. И. Ленин в поэзии народов мира. М.: Худлит, 1980. С. 266-268.

Gemeren R. van. Couperus. Een leven. Amsterdam: Prometeus, 2016. 958 p.

Gorter H. Liedjes. 1930. URL: http://www.dbnl.org/tekst/gort004lied01_01/ gort004lied01_01_0006.php (дата обращения: 20.01.2017). 
Roland Holst van der Schalk $H$. Het offer. Rotterdam: W. L. Brusse uitgeversmaatschappij, 1921. $120 \mathrm{p}$.

\section{REFERENCES}

Gemeren R.van. Couperus. Een leven. Amsterdam, Prometeus Publ., 2016. $958 \mathrm{p}$.

Gorter G. Imperializm, mirovaia voina i sotsial-demokratiia [Imperialism, World Wae and Social-democracy]. Moscow, Gosizdat, 1920. 152 p. (In Russian)

Gorter G. Istoricheskii materialism [Historical Materialism]. Moscow, Petrograd, Kommunist, 1919. 140 p. $2^{\text {nd }}$ edition. Moscow, Krasnaya nov' Publ., 1924. $3^{\text {nd }}$ ed. Moscow, Librokom Publ., 2011, 176 p. (In Russian)

Gorter H. Liedjes. 1930. Available at: http://www.dbnl.org/tekst/gort004lied01_01/gort004lied01_01_0006.php (accessed: 20.01.2017).

Lenin V.I. PSS. Izd-e 5-e. T. 49 PSS [Collected Works. 5th ed.]. Vol. 49. Moscow, Izd-vo politicheskoi literatury, 1970. 724 p. (In Russian)

Mikhailova I. M. O strategii perevodov niderlandskoi poezii v rannee sovetskoe vremia [On Strategy of Translation of Dutch poetry in Early Soviet Time]. Izvestiia Rossiiskogo gosudarstvennogo pedagogicheskogo universiteta im. A. I. Gertsena, 2008, no. 59, pp. 142-146. (In Russian)

Oshis V.V. Pod znakom sotsialisticheskikh idei: Niderlandskaia literatura na rubezhe XIX i XX vekov [Under the sign of socialist ideas: Dutch literature at the turn of the XIX and XX centuries]. Istoriia vsemirnoi literatury: $V 8 t$. Moscow, Nauka Publ., 1983-1994, vol. 8, 1994, pp.316-318. (In Russian)

Ot «Lisa Reinarda» do «Sna bogov»: istoriia niderlandskoi literatury [From 'Reynaert de vos' to 'Godenslaap. A history of Dutch literature]. St. Peterburg, Alexandria Publ., 2013, vol. I. XII - beginning XX century. 544 p.

Roland Gol'st van der Skhal'k G. Zhertva [Victim]. Transl. V. Reitts. Roland Gol'st van der Skhal'k G. Liricheskie dramy. Petrograd, Gosudarstvennoe izdatel'stvo, 1922, pp. 29-128. (In Russian)

Roland Holst van der Schalk H. Het offer. Rotterdam, W.L. Brusse uitgeversmaatschappij, 1921. $120 \mathrm{p}$.

Roland Kholst van der Skhalk G. Lenin. Transl. by A. Orlov. Ladon' poeta. Stikhi [The Hand of the Poet. Poems]. Moscow, Progress nPubl., 1964, pp. 93-94. (In Russian)

Roland Kholst van der Skhalk G. Lenin. Transl. by A. Orlov. V.I.Lenin v poezii narodov mira [V.I. Lenin in the Poetry of the Peoples of the World]. Moscow, Khudlit Publ., 1980, pp. 266-268. (In Russian) 


\section{Михайлова Ирина Михайловна}

доктор филологических наук, доцент, профессор,

Санкт-Петербургский государственный университет.

Российская Федерация, 199034, Санкт-Петербург,

Университетская наб., д. 7-9

E-mail: i.mikhailova@spbu.ru

\section{Irina Michajlova}

Doctor in Philology, Associate Professor,

St. Petersburg State University,

7-9, Universitetskaya nab., St. Petersburg, 199034, Russian Federation

E-mail: i.mikhailova@spbu.ru 